\title{
LAETITIA DION, Histoires de mariage. Le mariage dans la fiction narrative française (1515-1559)
}

\section{Maurizio Busca}

\section{(2) OpenEdition}

\section{Journals}

\section{Edizione digitale}

URL: https://journals.openedition.org/studifrancesi/22456

DOI: 10.4000/studifrancesi.22456

ISSN: 2427-5856

\section{Editore}

Rosenberg \& Sellier

\section{Edizione cartacea}

Data di pubblicazione: 1 avril 2020

Paginazione: 162

ISSN: 0039-2944

\section{Notizia bibliografica digitale}

Maurizio BUSCa, "LAETITIA DION, Histoires de mariage. Le mariage dans la fiction narrative française

(1515-1559)», Studi Francesi [Online], 190 (LXIV | I) | 2020, online dal 01 avril 2020, consultato il 03 août 2021. URL: http://journals.openedition.org/studifrancesi/22456 ; DOI: https://doi.org/10.4000/ studifrancesi.22456

Questo documento è stato generato automaticamente il 3 août 2021

\section{cc) (i) (2)}

Studi Francesi è distribuita con Licenza Creative Commons Attribuzione - Non commerciale - Non opere derivate 4.0 Internazionale. 


\title{
LAETITIA DION, Histoires de mariage. Le mariage dans la fiction narrative française (1515-1559)
}

\author{
Maurizio Busca
}

\section{NOTIZIA}

LAETITIA DION, Histoires de mariage. Le mariage dans la fiction narrative française (1515-1559), Paris, Classiques Garnier, 2017, «Bibliothèque de la Renaissance» 16, 588 pp.

1 Durante i primi due terzi del Cinquecento l'istituto del matrimonio diviene oggetto di controversie di carattere giuridico, religioso e politico; parallelamente, si moltiplicano le opere narrative che pongono al centro della fabula problemi legati alla formazione di una coppia e allo svolgimento della vita coniugale. Il saggio di Dion propone di considerare congiuntamente questi due fenomeni e di studiare le rappresentazioni del matrimonio nei generi narrativi associando gli strumenti dell'analisi letteraria (in primo luogo narratologica) a quelli dell'analisi storica: l'indagine condotta sul ruolo delle situazioni matrimoniali nelle strutture narrative delle tredici opere che compongono il corpus (romanzi, raccolte di novelle e di histoires tragiques) appare quindi informata da ricerche svolte nei campi della storia letteraria e della storia culturale.

2 La prima delle tre parti in cui si articola il volume ( $«$ L'histoire du mariage en France au XVII ${ }^{e}$ siècle. L'institution et ses représentations», pp. 45-142) è volta a presentare il contesto istituzionale, giuridico, ideologico e culturale in cui si inseriscono le opere analizzate. Il denso capitolo iniziale ripercorre la storia del matrimonio cristiano dall'antichità al Rinascimento, rilevando le cause e le dinamiche delle tensioni al centro delle quali questo istituto si viene a trovare alle soglie dell'età moderna. Il capitolo seguente è invece dedicato alle rappresentazioni del matrimonio nei testi non narrativi: dopo aver ricordato la vivacità di due correnti opposte, misogamia e filogamia, 
entrambe solidamente ancorate nella tradizione letteraria francese, vengono passate in rassegna opere di carattere didattico, morale e medico volte a definire la natura del legame coniugale e dei coniugi stessi, oltre che a normare la condotta che questi ultimi sono chiamati a rispettare. Per completare la panoramica della cornice intellettuale in cui è inscritto il corpus, sono infine presi in considerazione testi teatrali e poetici che sviluppano un discorso sul matrimonio. Si delinea così un quadro complesso, caratterizzato dalla presenza di forze antagoniste e segnato da eventi di ampia portata quali la Riforma, la costituzione dello stato monarchico e la trasformazione delle strutture sociali in corso nei decenni centrali del secolo. La seconda parte («Les composantes des histoires de mariage. Une matière narrative en mutation», pp. 143-332) definisce una tipologia delle situazioni matrimoniali, esaminando la natura del legame (matrimoni clandestini, politici o ancora di riparazione; arrangiati o osteggiati dai genitori; bene o male assortiti...), il ruolo esercitato dalle famiglie e dalle strutture sociali nella sua formazione, ed infine alcuni motivi ed episodi topici della vita coniugale (la notte di nozze; l'adulterio e le sue conseguenze; casi notevoli di armonia o di conflitto...). È possibile rintracciare, all'interno del corpus, modelli e tendenze diverse la cui evoluzione nel tempo può essere imputata al contesto della Controriforma: mentre l'eredità della tradizione franco-borgognona dei fabliaux e quella del Decameron è manifesta soprattutto nei primi decenni del secolo, a partire dalla metà degli anni ' 40 si ha una netta prevalenza di opere che condannano implicitamente le trasgressioni dell'ordine coniugale. La terza ed ultima parte ( $/ \mathrm{La}$ poétique des histoires de mariage. Le mariage au cœur des innovations du genre narratif», pp. 333-535) tratta del tema matrimoniale sia nel quadro del processo di creazione letteraria che in quello dell'evoluzione dei generi narrativi. I motivi del matrimonio clandestino e dell'adulterio, fondati su dinamiche di conflitto fra individui e autorità sociali e familiari, inducono all'approfondimento della dimensione psicologica e alla rappresentazione dei conflitti interni dei personaggi. Il trattamento di queste ed altre tematiche, inoltre, contribuisce all'emergenza di nuove forme narrative che, nei decenni seguenti, troveranno piena espressione nelle histoires tragiques, nei romanzi sentimentali e nei romans à tiroir. 